\title{
Long-term Risk of Malignant Neoplastic Disorders in Type 2 Diabetes Mellitus Patients with Metabolic Syndrome
}

This article was published in the following Dove Press journal: Diabetes, Metabolic Syndrome and Obesity: Targets and Therapy

\author{
Oana Albai ${ }^{1,2}$ \\ Mirela Frandes (iD ${ }^{3}$ \\ Bogdan Timar $\mathbb{D}^{2,3}$ \\ Diana-Loreta Paun ${ }^{4}$ \\ Deiana Roman (D) \\ Romulus Timar ${ }^{1,2}$
}

'Second Department of Internal Medicine, "Victor Babes" University of Medicine and Pharmacy, Timisoara, Romania; ${ }^{2}$ Department of Diabetes and Metabolic Diseases, "Pius Brinzeu" Emergency Hospital, Timisoara, Romania; ${ }^{3}$ Department of Functional Sciences, "Victor Babes" University of Medicine and Pharmacy, Timisoara, Romania; ${ }^{4}$ Department of Public Health, Department of Endocrinology, "Carol Davila" University of Medicine and Pharmacy, Bucuresti, Romania
Correspondence: Mirela Frandes Department of Functional Sciences, "Victor Babes" University of Medicine and Pharmacy, 2 Eftimie Murgu, Timisoara 30004I, Romania

Tel +40 73I I I 7020

$\mathrm{Fax}+40256462856$

Email mirela.frandes@umft.ro
Background: In developing countries, cancer incidence has progressively increased, becoming the second cause of mortality after cardiovascular diseases. Type 2 diabetes mellitus (T2DM) is associated with an increased risk of malignant neoplastic disorders, especially pancreatic cancer, colorectal cancer, and breast cancer.

Aim: The main aim of our study was to establish the prevalence of malignant neoplastic disorders in patients previously diagnosed with T2DM. Also, we have investigated the association between the components of the metabolic syndrome (MetS) and the different types of diagnosed malignant neoplasms.

Methods: We performed a retrospective, population-based cohort study of 1,027 patients with T2DM from the Center for Diabetes Treatment of the "Pius Brînzeu" Emergency Hospital in Timisoara, Romania. The patients were followed up every three or six months, depending on their antidiabetic treatment. The patients who developed malignant neoplasms were registered and referred to oncology centers. The potential risk factors for malignancies in patients with T2DM were evaluated using logistic regression adjusting for possible confounders.

Results: The prevalence of malignant neoplastic disorders in our study group was $7.1 \%$; more precisely, we found $2.2 \%$ colon neoplasm, $2.9 \%$ mammary neoplasm, $0.7 \%$ lymphomas, $0.6 \%$ pulmonary neoplasm, $0.3 \%$ pancreatic neoplasm, and $0.4 \%$ prostate neoplasm. The presence of malignant neoplastic disorders was associated in our cohort of patients with T2DM with higher cholesterol $(237.71 \pm 47.82$ vs $202.52 \pm 52.16 \mathrm{mg} / \mathrm{dL}$; $\mathrm{p}=0.005)$ and triglycerides levels $(215.91$ $\pm 52.41 \mathrm{vs} 180.75 \pm 54.32 \mathrm{mg} / \mathrm{dL} ; \mathrm{p}<0.001)$, as well as higher body mass index $(33.37 \pm 3.87 \mathrm{vs}$ $\left.28.42 \pm 3.56 \mathrm{~kg} / \mathrm{m}^{2} ; \mathrm{p}<0.001\right)$ and abdominal circumference $(110.11 \pm 14.48 \mathrm{vs} 98.12 \pm 15.73 \mathrm{~cm}$; $\mathrm{p}<0.001)$. Also, we found that insulin-based treatment was an independent risk factor, the patients presenting ten times higher odds of developing malignant neoplastic disorders.

Conclusion: The prevalence of malignant neoplastic disorders in our study group was $7.1 \%$. Also, the prevalence of malignant neoplastic disorders was higher in patients with T2DM and MetS as compared to the general population of T2DM patients.

Keywords: malignant neoplastic disorders, type 2 diabetes mellitus, hyperinsulinemia, metabolic syndrome, insulin resistance

\section{Introduction}

Cancer remains a global health issue, tending to become the leading mortality cause of the adult population. ${ }^{1}$ Cancer incidence may rise by as much as with $50 \%$ to a staggering 15 million new cases in 2020, according to the World Cancer Report. In 2000, malignant tumors accounted for $12 \%$ of the 56 million deaths of all causes 
worldwide. Numerous countries attribute more than a quarter of the deaths to neoplastic disorders. ${ }^{2}$

The main risk factors that contribute to the genesis of malignancies can be classified as modified and non-modified. The non-modified factors include sex, age, ethnicity, genetic inheritance, etc. The modified risk factors are smoking, sedentary life, alcohol consumption, diet, poverty, different infections, type 2 diabetes mellitus (T2DM) ${ }^{3-8}$

Chronic hyperglycemia (endogenous or post-therapeutic), hyperinsulinemia and chronic inflammation present in T2DM facilitate neoplastic proliferation. Chronic hyperglycemia leads to the formation of reactive oxygen species (ROS), advanced glycosylation end-products (AGE) with their interaction with RAGE receptors and the hypoactivation of the phosphatidylinositol 3-kinase/protein kinase B pathway. The Warburg hypothesis underlining the dependency of cancerous cells on glycolysis in order to obtain energy is well known and leads to the conclusion that cancer cells require high glucose levels. ${ }^{9-11}$

Overweight, the major component of Metabolic Syndrome (MetS), and obese individuals have a higher risk of developing all types of cancer compared to those of normal weight. ${ }^{12,13}$ Insulin-resistance (IR) represents the common pathogenic element of MetS. The adipose tissue is an active endocrine organ that produces free fatty acids (FFAs), interleukin-6 (IL-6), monocyte chemoattractant protein, plasminogen activator inhibitor 1 (PAI-1), adiponectin, leptin, and tumor necrosis factor $\alpha(\mathrm{TNF}-\alpha)$. These molecules increase the expression of PAI-1, activate the transductor and transcription of protein via cytokines (IL-6), the increased proliferation, invasion, and survival of cancer cells, decreasing the host's antitumor immunity. ${ }^{13,14}$ Also, we encounter a prothrombotic state (PAI-1, coagulation factors), and a proinflammatory state (increased PCR, increased levels of TNF$\alpha$, IL-6, decreased plasma level of adiponectin). ${ }^{15-17}$ Adipose tissue accumulates in small quantities in the visceral region, consequently its volume increases, its ectopic disposition enlarges, and it becomes dysfunctional. The ectopic disposition of adipose tissue takes place in muscles, the pancreas, the liver, the pericardium, and the perivascular region. Its dysfunctionality refers to the adipocyte ability to secrete prothrombotic and pro-inflammatory adipokines, thus contributing to the occurrence and aggravation of IR, diabetogenesis, and atherogenesis. ${ }^{18-20}$

Given this serious increase in the number of patients suffering from malignant neoplasm, the main aim of our study was to investigate its prevalence in T2DM patients. We have also investigated the presence of MetS in our group, attempting to identify the relationship between metabolic aspects and malignant neoplasm in T2DM patients.

\section{Patients and Methods Study Design and Patients}

In this study, 1,027 patients previously diagnosed with T2DM were enrolled. They were attending scheduled visits to the Centre for Diabetes Treatment of the "Pius Brînzeu" Emergency Hospital in Timisoara, Romania. The observation period was between 2015 and 2018. The study was conducted in accordance with the Declaration of Helsinki, and the protocol of our study was approved by the "Pius Brînzeu" Emergency Hospital Timisoara Ethics Committee.

All the patients included in the study provided written informed consent for the acquisition, analysis, and publication of the anonymous data collected during their hospital admission.

The exclusion criteria were the following: age under 18 (given that there were T2DM patients), and, for the sake of correct monitoring and high compliance (since the patients had to attend their regularly scheduled visits), the patients with failure of renal function with GFR under $45 \mathrm{~mL} / \mathrm{min}$ or in renal replacement therapy, the patients with severe psychiatric disorders, as well as those with acute cardiovascular events.

\section{Clinical, Anthropometric and Laboratory Data}

MetS clinical picture is highly heterogeneous, being mostly dominated by obesity/overweight. Currently, the MetS concept displays numerous biochemical and clinical anomalies: 1) abdominal obesity; 2) Insulin-resistance, recognized as the etiopathogenic element of MetS and subsequent hyperinsulinemia; 3) Glucose tolerance alteration: modification of basal glycemia, lower glucose tolerance, T2DM; 4) Atherosclerosis dyslipidemia: fasting hypertriglyceridemia; a postprandial increase of plasmatic concentration of triglyceride-rich lipoproteins (TG); lower plasmatic HDLc; a higher percentage of small and dense oxidation susceptible and intensely atherosclerotic LDL; the increased plasma concentration of apolipoprotein B; 5) Hyperuricemia; 6) Prothrombotic, hypofibrinolytic state: reduction of the fibrinolytic activity due to higher plasma levels of the plasminogen tissue activator inhibitor (PAI-1); increased fibrinogen plasma levels; increased plasma levels of von Willebrand 
factor and VII factor; increased blood viscosity; 7) Endothelial dysfunction: high level of cell adhesion molecules, lower endothelium-dependent vasodilation, nitric oxide-mediated (NO); microalbuminuria; 8) Subclinical chronic inflammation: increased plasma levels of proinflammatory cytokines: IL-6, IL-1, TNF; increased plasma levels of acute-phase proteins: $\mathrm{C}$ reactive protein, fibrinogen; 9) Hyperleptinemia; 10) Non-alcoholic fatty liver disease (hepatic steatosis, non-alcoholic steatohepatitis, steatofibrosis); 11) Hemodynamic changes: increased activity of the sympathetic nervous system; increased activity of the reninangiotensin-aldosterone system.

The MetS diagnosis is established based on the occurrence of any three criteria out of the five ones below:

- Fasting glycemia $\geq 100 \mathrm{mg} / \mathrm{dl}$ or treatment for dysglycemia

- Abdominal circumference (CFA) $\geq 80 \mathrm{~cm}$ (women) or $\geq 94 \mathrm{~cm}$ (men)

- Blood pressure $\geq 130 / \geq 85 \mathrm{mmHg}$ or hypertension treatment

- $\mathrm{TG} \geq 150 \mathrm{mg} / \mathrm{dl}$ or lipid-lowering medication

- HDLc $<40 \mathrm{mg} / \mathrm{dl}$ (men) or $<50 \mathrm{mg} / \mathrm{dl}$ (women) or current treatment.

MetS components act synergistically, and they cumulate, promoting proliferative processes.

The lipid profile and the presence of other co-morbidities, such as hepatitis, were assessed for all patients included. We have also collected data related to diabetic history from the patients' medical records. We assessed the weight status by computing the BMI as the weight (in kilograms) divided by the square of the height (in meters). Hypertension was present when systolic blood pressure was higher than 140 $\mathrm{mmHg}$ and/or diastolic blood pressure was over $90 \mathrm{mmHg}$ or irrespective of its value in patients under antihypertensive treatment. We considered dyslipidemia (blood lipids disorder) when total cholesterol was higher than $200 \mathrm{mg} / \mathrm{dL}$ and/ or HDL cholesterol was less than $45 \mathrm{mg} / \mathrm{dL}$ and/or LDL cholesterol was greater than $100 \mathrm{mg} / \mathrm{dL}$ and/or triglycerides were greater than $150 \mathrm{mg} / \mathrm{dL}$.

Triglycerides, HDL cholesterol, and total cholesterol levels were measured using an automatic enzymatic (CobasMira Roche) analyzer. LDL cholesterol was calculated according to the Friedewald formula when triglycerides levels were under $400 \mathrm{mg} / \mathrm{dL}$. The HbA1c level was measured using an NGSP-standardized and DCCT-compliant immunoturbidimetric assay (Roche), including an intra assay variation coefficient of $1.64 \%$, according to the manufacturer's specifications. Hepatic disorders include a broad spectrum of entities, from single hepatic steatosis to cirrhosis, with severe complications.

\section{Assessment of Neoplasms}

For accurate cancer diagnosis, the difference between benign and malignant must be made. A specific diagnosis is based on laboratory tests (blood count, inflammatory markers: ESR, PCR, fibrinogen, etc.) specific tumor markers (ACE, CA 19-9, CA 125, CA 153, PSA alpha-fetoprotein, etc.), as well as imaging methods: CT scans, MRI scans, PET scans, mammograms, ultrasounds, endoscopy, X-Rays. Histopathological tests were carried out in order to accurately establish the neoplasm type. Based on all the tests performed, the patients were registered, monitored, and hospitalized in Specialized Oncology Clinics, following the specific treatment to each type of neoplasia.

Based on all the tests performed, it has been established the diagnostic of malignant neoplastic disease and the patients were registered, monitored, and hospitalized in Specialized Oncology Clinics, following the specific treatment to each type of neoplasia.

\section{Statistical Analysis}

Data were analyzed using the SPSS v.20 software (SPSS Inc., Chicago, IL, USA). We presented the continuous variables with Gaussian distribution as mean ( \pm standard deviation), while the continuous variables without Gaussian distribution were expressed as median (interquartile range). Categorical variables were presented as absolute frequency (percentage). The distributions of continuous variables were tested for normality using the Kolmogorov-Smirnov test. The equality of variances was assessed using the Levene's test.

The significance of the differences between groups with and without malignant neoplastic disorders was assessed by applying the Student's $t$-test for means (Gaussian populations), Mann-Whitney $U$-test for medians (non-Gaussian populations), or Pearson chi-square (or Fisher exact test) for proportions. The significance of the association between the presence of long-term MetS in T2DM patients and the presence of malignant neoplastic disorders was assessed by applying logistic regression analysis. The influence of confounding factors in the dichotomous outcomes was assessed by adjusting for covariates in multivariate logistic regression models. We computed the odds ratios (OR) and 95\% confidence intervals $(95 \% \mathrm{CI})$ for each predictive variable. The 
continuous variables were assessed for linearity with respect to the logit of the dependent variable using the Box-Tidwell method.

We considered a $P$-value $<0.05$ as the threshold for statistical significance, and a confidence level of 0.95 for estimating intervals.

\section{Results}

A sample of 1,027 patients with T2DM, aged between 41 and 88 years, mean age $66.28( \pm 10.02)$ years, was considered. Almost half of the patients were males $43.4 \%$, mean age of $65.91( \pm 10.2), 95 \%$ CI $(64.96 ; 66.86)$, while $50.4 \%$ were females, mean age of $66.56( \pm 9.9), 95 \% \mathrm{CI}$ $(65.76 ; 67.37)$. The patients' baseline characteristics are presented in Table 1.

We observed that $22.3 \%$ of the patients were smokers, while $13 \%$ were frequent alcohol consumers. Also, we observed that most of the patients were hypertensive at stage I (57.6\%), while $17.7 \%$ were at stage II, and 5\% were at a pre-hypertensive stage.

We assessed the lipid profile, the presence of MetS, the presence of other co-morbidities, such as hepatitis, and the presence of malignant neoplasms for all the included patients.

We observed that $17.8 \%$ of the patients presented hepatic steatosis, while $0.5 \%$ presented hepatitis $\mathrm{B}$, and $1.8 \%$ presented hepatitis C. Most of the patients followed a treatment with oral antidiabetic drugs (71.5\%), from which $74.9 \%$ used a treatment containing metformin, $66.2 \%$ containing sulfonylureas, and $7.2 \%$ containing incretins.

We found that $73(7.1 \%)$ of the diabetic patients presented a type of malignant neoplasm, more precisely, $2.2 \%$ presented colon neoplasm, $2.9 \%$ presented mammary neoplasm, $0.7 \%$ presented lymphomas, $0.6 \%$ presented pulmonary neoplasm, $0.3 \%$ presented pancreatic neoplasm, and $0.4 \%$ presented prostate neoplasm.

We compared the group of patients with colorectal cancer vs patients without colorectal cancer. We did not observe differences between their age, gender distribution, percentage of smokers, and alcohol consumers (Table 2). On the contrary, we observed significant differences between the two groups when considering the MetS components. More precisely, we noticed that patients with malignant dysplasia presented significantly lower values of HDL cholesterol than patients without malignant dysplasia, 41.00 (34.00-47.00) vs 45.00 (39.00- 56.00) (Mann-Whitney $U$-test, $\mathrm{p}=0.033$ ). Also, we observed that the triglycerides level was significantly higher in the group of patients with colorectal cancer, 222.00 (185.00-
Table I Baseline Characteristics of the Patients

\begin{tabular}{|c|c|}
\hline Number of patients & 1027 \\
\hline Age (years) ${ }^{(\mathrm{a})}$ & $66.28( \pm 10.02)$ \\
\hline Gender $(\text { male })^{c}$ & $446(43.40 \%)$ \\
\hline BMI $\left(\mathrm{kg} / \mathrm{m}^{2}\right)^{\mathrm{a}}$ & $31.70( \pm 4.60)$ \\
\hline $\mathrm{AC}(\mathrm{cm})^{\mathrm{b}}$ & $109.00(97.00-120.00)$ \\
\hline Smoking ${ }^{c}$ & $227(22.30 \%)$ \\
\hline Alcohol $^{c}$ & 134 (I3.00\%) \\
\hline \multicolumn{2}{|l|}{ Alcohol consumption ${ }^{c}$} \\
\hline Frequently & $34(3.31 \%)$ \\
\hline Occasionally & $100(9.74 \%)$ \\
\hline Total cholesterol $(\mathrm{mg} / \mathrm{dL})^{\mathrm{a}}$ & $231.51( \pm 50.13)$ \\
\hline HDLc (mg/dL) $)^{a}$ & $47.53( \pm 13.06)$ \\
\hline $\operatorname{LDLc}(\mathrm{mg} / \mathrm{dL})^{\mathrm{a}}$ & $145.63( \pm 46.30)$ \\
\hline DM duration (years) ${ }^{\mathrm{b}}$ & $10.00(6.00-14.00)$ \\
\hline $\mathrm{HbAlc}(\%)^{\mathrm{b}}$ & $8.20(7.50-8.95)$ \\
\hline Triglycerides $(\mathrm{mg} / \mathrm{dL})^{\mathrm{b}}$ & $181.00(143.50-215.00)$ \\
\hline \multicolumn{2}{|l|}{$\mathrm{HBP}^{\mathrm{c}}$} \\
\hline Normal & 401 (19.06\%) \\
\hline Prehypertension & $39(5 \%)$ \\
\hline Hypertension stage I & 449 (57.6\%) \\
\hline Hypertension stage II & $138(17.7 \%)$ \\
\hline \multicolumn{2}{|l|}{ DM treatment ${ }^{c}$} \\
\hline OAD (oral antidiabetic drugs) & 734 (71.5\%) \\
\hline Insulin & $150(14.6 \%)$ \\
\hline OAD and insulin & $143(13.9 \%)$ \\
\hline Neoplam ${ }^{c}$ & $73(7.1 \%)$ \\
\hline \multicolumn{2}{|l|}{ Hepatitis $^{c}$} \\
\hline Hepatic steatosis & I83 (I7.80\%) \\
\hline Hepatitis B & $5(0.50 \%)$ \\
\hline Hepatitis C & $18(1.80 \%)$ \\
\hline
\end{tabular}

Notes: ${ }^{2}$ Continuous variables (with Gaussian distribution) are indicated by their mean (standard deviation); ${ }^{\mathrm{b}}$ continuous variables (with non-Gaussian distribution) are indicated by their median (interquartile range); ${ }^{c}$ categorical variables are presented by absolute frequency (percentage) in the sample.

Abbreviations: DM, diabetes mellitus; BMI, body mass index; AC, abdominal circumference; HDLc, high-density lipoprotein cholesterol; LDLc, low-density lipoprotein cholesterol; HBP, high blood pressure; OAD, oral antidiabetic drugs.

273.00) vs $178.00(148.00$ - 214.50), (Mann-Whitney $U$-test, $\mathrm{p}=0.007)$. Moreover, the group with colorectal cancer presented significantly higher BMI and AC than the group without colorectal cancer, 39.74 (4.93) vs 31.79 (4.07) (Mann-Whitney $U$-test, $\mathrm{p}=0.024)$, and 132.00 $(122.00-138.00)$ vs 105.00 (97.00- 118.00) (MannWhitney $U$-test, $\mathrm{p}=0.005)$, respectively.

At the same time, we compared the group of patients with breast cancer vs patients without breast cancer. Similar to the previous comparison, we did not observe differences between their age, gender distribution, 
Table 2 Comparison Between Groups: T2DM Patients Without Colorectal Cancer vs T2DM Patients with Colorectal Cancer

\begin{tabular}{|c|c|c|c|}
\hline Parameters & Without Colorectal Cancer & With Colorectal Cancer & \multirow[t]{2}{*}{$P$-value } \\
\hline Number of patients & 1004 (97.8\%) & $23(2.2 \%)$ & \\
\hline Age (years) ${ }^{\mathrm{b}}$ & $65.00(58.00-73.00)$ & $67.00(60.00-75.00)$ & 0.450 \\
\hline Gender (male) ${ }^{c}$ & $434(43.2 \%)$ & $12(52.2 \%)$ & 0.392 \\
\hline BMI $\left(\mathrm{kg} / \mathrm{m}^{2}\right)^{\mathrm{a}}$ & $31.79( \pm 4.07)$ & $39.74( \pm 4.93)$ & 0.024 \\
\hline $\mathrm{AC}(\mathrm{cm})^{\mathrm{b}}$ & $105.00(97.00-118.00)$ & $132.00(122.00-138.00)$ & 0.005 \\
\hline Smoking ${ }^{c}$ & $219(22 \%)$ & $8(34.8 \%)$ & 0.146 \\
\hline Alcohol $^{c}$ & $128(12.7 \%)$ & $6(26.1 \%)$ & 0.106 \\
\hline DM duration (years) ${ }^{\mathrm{b}}$ & $10.00(6.00-14.00)$ & $10.00(6.00-14.00)$ & 0.244 \\
\hline $\mathrm{HbAlc}(\%)^{\mathrm{b}}$ & $8.20(7.55-9.00)$ & $8.55(8.20-9.40)$ & 0.412 \\
\hline Triglycerides $(\mathrm{mg} / \mathrm{dL})^{\mathrm{b}}$ & $178.00(|48.00-2| 4.50)$ & $222.00(185.00-273.00)$ & 0.007 \\
\hline Total cholesterol $(\mathrm{mg} / \mathrm{dL})^{\mathrm{b}}$ & 231.00 (199.50-272.00) & $214.50(187.00-240.00)$ & 0.001 \\
\hline HDLc (mg/dL) ${ }^{b}$ & $45.00(39.00-56.00)$ & $41.00(34.00-47.00)$ & 0.033 \\
\hline LDLc (mg/dL) ${ }^{\mathrm{b}}$ & 143.00 (124.00-184.90) & $124.00(81.00-146.40)$ & 0.186 \\
\hline Hypertension $^{c}$ & $812(80.9 \%)$ & 21 (9l.3\%) & $<0.001$ \\
\hline \multicolumn{4}{|l|}{ DM treatment ${ }^{c}$} \\
\hline OAD & $720(71.7 \%)$ & 14 (59.8\%) & 0.255 \\
\hline Insulin & $142(14.1 \%)$ & $8(34.8 \%)$ & 0.024 \\
\hline ADO and insulin & 142 (|14.1\%) & I (4.3\%) & 0.294 \\
\hline Metformin $^{c}$ & 756 (75.3\%) & 13 (56.5\%) & 0.040 \\
\hline Sulfonylureas ${ }^{c}$ & 665 (66.2\%) & 15 (65.2\%) & 0.090 \\
\hline Incretins ${ }^{c}$ & 74 (7.4\%) & $0(0.0 \%)$ & 0.402 \\
\hline
\end{tabular}

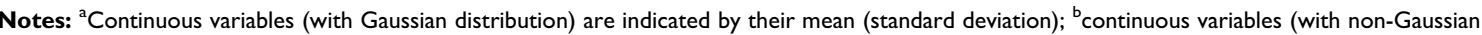
distribution) are indicated by their median (interquartile range); 'categorical variables are presented by absolute frequency (percentage) in the sample; ${ }^{d} p$-value was computed using the Mann-Whitney U-test for continuous variables (with non-Gaussian distribution) and Pearson Chi-Square test or Fisher's exact test for nominal variables.

Abbreviations: DM, diabetes mellitus; BMI, body mass index; AC, abdominal circumference; HDLc, high-density lipoprotein cholesterol; LDLc, lowdensity lipoprotein cholesterol; HBP, high blood pressure; OAD, oral antidiabetic drugs.

percentage of smokers, and alcohol consumers (Table 3). On the contrary, we observed significant differences between the two groups when considering the MetS components. More precisely, we observed that patients with breast cancer presented significantly higher values of LDL cholesterol than patients without breast cancer, 147.10 (117.90-185.20) vs $126.10 \quad(89.70-137.00)$ (MannWhitney $U$-test, $\mathrm{p}=0.019$ ). Also, we observed that the triglycerides level was significantly higher in the group of patients with breast cancer, $185.50(150.00-215.00)$ vs 129.00 (14.50- 191.50), (Mann-Whitney $U$-test, p = 0.041). Moreover, the group of patients with cancer presented significantly higher BMI and AC than the group without cancer, $35.13(28.92-38.88)$ vs 28.50 (24.9532.38) (Mann-Whitney $U$-test, $\mathrm{p}=0.033$ ), and 119.00 $(107.00-123.00)$ vs 106.00 (89.50- 117.00) (MannWhitney $U$-test, $\mathrm{p}=0.004)$, respectively.

Hypertension was significantly more present in the group of T2DM patients with breast cancer than the group of patients without breast cancer, 28 (93.33\%) vs 810 (81.2\%), Fisher's exact test, $p<0.001$. Regarding the antidiabetic treatment, we found that significantly more patients with insulin-based treatment presented breast cancer, 9 $(30 \%)$ vs 141 (14.1\%), Chi-square test, $\mathrm{p}=0.043$.

We analyzed the effect of body mass and abdominal distribution of adipose tissue on the presence of malignant neoplastic affections by considering the average values of BMI and AC. Also, we studied the impact of lipid parameters on the presence of neoplastic affections by taking into account the average values of cholesterol as well as the average values of triglycerides. Moreover, we also investigated the influence of hypertension and insulin-based treatment over the presence of malignant neoplastic affections.

We compared the group of T2DM patients without malignant neoplasia vs T2DM patients with malignant neoplasia (Table 4). We observed no significant differences between their age, gender distribution, and percentages of smokers and alcohol consumers. On the contrary, 
Table 3 Comparison Between Groups: T2DM Patients Without Breast Cancer vs T2DM Patients with Breast Cancer

\begin{tabular}{|c|c|c|c|}
\hline \multirow[t]{2}{*}{ Number of patients } & Without Breast Cancer & With Breast Cancer & \multirow[t]{2}{*}{$P$-value ${ }^{d}$} \\
\hline & 997 (97.1\%) & $30(2.9 \%)$ & \\
\hline Age (years) ${ }^{b}$ & $66.00(60.00-72.00)$ & $68.00(59.50-76.00)$ & 0.807 \\
\hline Gender (male) ${ }^{c}$ & $422(42.32 \%)$ & $0(0 \%)$ & $<0.001$ \\
\hline BMI $\left(\mathrm{kg} / \mathrm{m}^{2}\right)^{\mathrm{b}}$ & $28.50(24.95-32.38)$ & $35.13(28.92-38.88)$ & 0.033 \\
\hline $\mathrm{AC}(\mathrm{cm})^{\mathrm{b}}$ & $106.00(89.50-117.00)$ & $119.00(107.00-123.00)$ & 0.004 \\
\hline Smoking ${ }^{c}$ & $222(22.5 \%)$ & $5(16.7 \%)$ & 0.656 \\
\hline Alcohol $^{c}$ & I 34 (I3.44\%) & 4 (I3.33\%) & 0.325 \\
\hline DM duration (years) ${ }^{\mathrm{b}}$ & $10.00(6.00-14.00)$ & $12.50(9.00-16.00)$ & 0.029 \\
\hline $\mathrm{HbAlc}(\%)^{\mathrm{b}}$ & $8.20(7.50-9.00)$ & $8.35(7.95-8.40)$ & 0.882 \\
\hline Triglycerides $(\mathrm{mg} / \mathrm{dL})^{\mathrm{b}}$ & $129.00(\mid 4.50-191.50)$ & $185.50(\mid 50.00-215.00)$ & 0.041 \\
\hline Total cholesterol $(\mathrm{mg} / \mathrm{dL})^{\mathrm{b}}$ & $234.00(198.00-273.50)$ & $204.50(165.00-243.50)$ & 0.021 \\
\hline HDLc (mg/dL) ${ }^{b}$ & $46.00(38.00-56.00)$ & $46.00(39.50-48.00)$ & 0.143 \\
\hline $\operatorname{LDLc}(\mathrm{mg} / \mathrm{dL})^{\mathrm{b}}$ & $126.10(89.70-137.00)$ & 147.10 (|17.90-185.20) & 0.019 \\
\hline Hypertension ${ }^{c}$ & $810(81.2 \%)$ & $28(93.33 \%)$ & $<0.001$ \\
\hline \multicolumn{4}{|l|}{ DM treatment ${ }^{c}$} \\
\hline OAD & $714(71.6 \%)$ & $19(63.3 \%)$ & 0.332 \\
\hline Insulin & $14 \mid(14.1 \%)$ & $9(30 \%)$ & 0.043 \\
\hline OAD and insulin & $|4|(\mid 4.1 \%)$ & $2(6.7 \%)$ & 0.375 \\
\hline Metformin ${ }^{c}$ & 752 (75.4\%) & 17 (56.7\%) & 0.020 \\
\hline Sulfonylureas ${ }^{c}$ & $665(66.7 \%)$ & $15(50 \%)$ & 0.057 \\
\hline Incretins ${ }^{c}$ & 73 (7.3\%) & I (3.3\%) & 0.718 \\
\hline
\end{tabular}

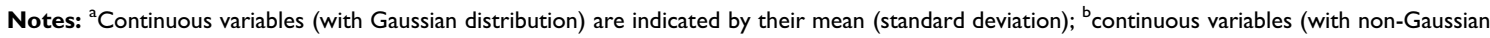
distribution) are indicated by their median (interquartile range); 'categorical variables are presented by absolute frequency (percentage) in the sample; ${ }^{\mathrm{d}} \mathrm{p}$-value was computed using the Mann-Whitney U-test for continuous variables (with non-Gaussian distribution) and Pearson Chi-Square test or Fisher's exact test for nominal variables.

Abbreviations: DM, diabetes mellitus; BMI, body mass index; AC, abdominal circumference; HDLc, high-density lipoprotein cholesterol; LDLc, lowdensity lipoprotein cholesterol; HBP, high blood pressure; OAD, oral antidiabetic drugs.

we observed significant differences their MetS components, namely, BMI, AC, triglycerides, HDLc, LDLc. Also, we observed that T2DM patients with malignant neoplastic disorders had significant longer DM duration and also, significant higher percentages of patients with insulin-based treatment.

In the univariate logistic regression models, we identified DM duration as a significant risk factor for the presence of malignant neoplastic affections $(\mathrm{OR}=1.045,95 \% \mathrm{CI}$ : $1.001-1.090, \mathrm{p}=0.043)$. Also, we found that independently $\mathrm{BMI}$ and $\mathrm{AC}$ were not significant risk factors. Regarding the lipid profile, we noticed that increased HDLc values were a significant protective factor $(\mathrm{OR}=0.941 ; 95 \% \mathrm{CI}$ : $0.908-$ 0.975; $\mathrm{p}<0.001)$. On the contrary, increased LDLc values were a significant risk factor $(\mathrm{OR}=1.041$; 95\% CI: $1.008-$ 1.075; $\mathrm{p}=0.001)$. Independently, triglycerides level was not a risk factor $(\mathrm{OR}=0.998,95 \% \mathrm{CI}$ : 0.994-1.003, $\mathrm{p}=0.489)$. On the contrary, hypertension was a significant risk factor for the presence of malignant neoplastic affections $(\mathrm{OR}=$ $1.405,95 \%$ CI:1.004-1.966, $\mathrm{p}=0.048)$. Also, insulin-based treatment was a significant risk factor $(\mathrm{OR}=1.515,95 \%$ CI:1.004-2.559, p <0.001).

We derived binomial logistic regression models for assessing the effects of the MetS components on the likelihood that T2DM patients have developed malignant neoplastic affections. The continuous variables were checked for linearity concerning the logit of the dependent variable by applying the Box-Tidwell procedure. A Bonferroni correction was applied, resulting in statistical significance being accepted when $\mathrm{p}<0.00625$. In consequence, the continuous independent variables were linearly related to the logit of the dependent variable. The final regression model was statistically significant, $\chi^{2}(8)=75.283, \mathrm{p}<0.001$, with a Nagelkerke coefficient $\mathrm{R}^{2}=0.586$; so, the model explained $58.6 \%$ of the variance in the presence of malignant neoplastic affections among T2DM patients. Moreover, the Hosmer and Lemeshow goodness of fit test indicated that our model was not a poor fit.

We have investigated possible confounding factors, and we observed that there was no statistically significant difference with regard to age, gender, smoking behavior, 
Table 4 Comparison Between Groups: T2DM Patients Without Malignant Neoplasia vs T2DM Patients with Malignant Neoplasia

\begin{tabular}{|c|c|c|c|}
\hline \multirow[t]{2}{*}{ Number of patients } & Without Malignant Neoplasia & With Malignant Neoplasia & \multirow[t]{2}{*}{$P$-value ${ }^{d}$} \\
\hline & 954 (92.9\%) & $73(7.1 \%)$ & \\
\hline Age (years)a & $64.77( \pm 7.79)$ & $68.71( \pm 10.01)$ & 0.295 \\
\hline Gender $(\mathrm{male})^{\mathrm{c}}$ & $417(43.7 \%)$ & $29(39.7 \%)$ & 0.438 \\
\hline BMI $\left(\mathrm{kg} / \mathrm{m}^{2}\right)^{\mathrm{a}}$ & $28.42( \pm 0.56)$ & $33.37( \pm 0.87)$ & $<0.001$ \\
\hline$A C(\mathrm{~cm}) \mathrm{a}$ & $98.12( \pm 15.73)$ & $110.11( \pm \mid 4.48)$ & $<0.001$ \\
\hline Smoking ${ }^{c}$ & $211(22.3 \%)$ & $16(22.2 \%)$ & 0.987 \\
\hline Alcohol $^{c}$ & $125(13.1 \%)$ & $9(12.3 \%)$ & 0.850 \\
\hline DM duration $\left(\right.$ years) ${ }^{\mathrm{b}}$ & $9.00(7.00-12.00)$ & $14.00(9.00-16.00)$ & 0.035 \\
\hline $\mathrm{HbAlc}(\%)^{\mathrm{b}}$ & $8.20(7.30-8.90)$ & $8.40(8.10-8.70)$ & 0.466 \\
\hline Triglycerides $(\mathrm{mg} / \mathrm{dL})^{\mathrm{a}}$ & $180.75( \pm 54.32)$ & $215.91( \pm 52.41)$ & $<0.001$ \\
\hline Total cholesterol $(\mathrm{mg} / \mathrm{dL})^{\mathrm{a}}$ & $202.52( \pm 52.16)$ & $237.71( \pm 47.82)$ & 0.005 \\
\hline HDLc $(m g / d L)^{a}$ & $48.96( \pm 12.92)$ & $43.62( \pm 13.11)$ & $<0.001$ \\
\hline $\operatorname{LDLc}(\mathrm{mg} / \mathrm{dL})^{\mathrm{a}}$ & || $5.5 \mid( \pm 40.36)$ & $151.91( \pm 45.13)$ & $<0.001$ \\
\hline Hypertension ${ }^{c}$ & $772(80.9 \%)$ & $63(86.3 \%)$ & 0.256 \\
\hline \multicolumn{4}{|l|}{ DM treatment ${ }^{c}$} \\
\hline OAD & $690(72.3 \%)$ & 43 (58.9\%) & 0.014 \\
\hline Insulin & 124 (13.0\%) & $26(35.6 \%)$ & $<0.001$ \\
\hline OAD and insulin & 140 (I4.7\%) & $3(4.1 \%)$ & 0.012 \\
\hline Metformin $^{c}$ & 729 (76.4\%) & $40(54.8 \%)$ & $<0.001$ \\
\hline Sulfonylureas ${ }^{c}$ & 643 (67.4\%) & $37(50.7 \%)$ & 0.004 \\
\hline Incretins ${ }^{c}$ & 71 (7.4\%) & $3(4.1 \%)$ & 0.289 \\
\hline
\end{tabular}

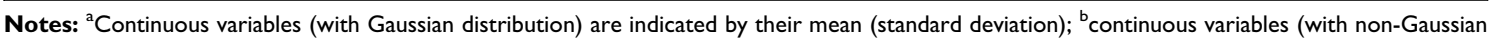
distribution) are indicated by their median (interquartile range); 'categorical variables are presented by absolute frequency (percentage) in the sample; ${ }^{\mathrm{d}} \mathrm{p}$-value was computed using the Mann-Whitney U-test for continuous variables (with non-Gaussian distribution) and Pearson Chi-Square test or Fisher's exact test for nominal variables.

Abbreviations: DM, diabetes mellitus; BMI, body mass index; AC, abdominal circumference; HDLc, high-density lipoprotein cholesterol; LDLc, lowdensity lipoprotein cholesterol; HBP, high blood pressure; OAD, oral antidiabetic drugs.

alcohol consumption, DM treatment based on OAD (such as, metformin, sulfonylureas, incretins) between T2DM patients who had developed malignant neoplasms and those who had not.

We found that patients with longer DM duration presented 1.112 times higher odds of developing malignant neoplastic affections than patients with shorter DM duration (OR = 1.112, 95\% CI: 1.083-1.258) (Table 5). Both body mass and abdominal circumference were significant risk factors, $(\mathrm{OR}=$ 1.014, 95\% CI: $1.001-1.075)$ and $(\mathrm{OR}=1.029,95 \%$ CI: 1. 017-1.102), respectively. Triglycerides level was neither a protective nor a risk factor. Higher HDLc was associated with a decreased likelihood of developing malignant neoplastic affections ( $\mathrm{OR}=0.902,95 \%$ CI: 0.843-0.964), but higher LDLc was correlated with an increased likelihood of neoplastic affections $(\mathrm{OR}=1.108,95 \% \mathrm{CI}$ : $1.031-1.210)$. Also, we observed that patients with hypertension had 10.187 times higher odds of developing neoplastic affections than patients without hypertension (OR $=10.187,95 \%$ CI: $2.123-18.873)$.
Moreover, the existence of an insulin-based treatment resulted in 10.585 times higher odds of developing malignant neoplastic disorders.

Table 5 MetS Related Predictors of Malignant Neoplasms in Patients with T2DM (Multivariate Logistic Regression Model; Nagelkerke $\mathrm{R}^{2}=0.586$ )

\begin{tabular}{|l|l|l|l|}
\hline \multirow{2}{*}{ Variable } & \multirow{2}{*}{ OR } & \multicolumn{2}{|l|}{$95 \%$ Cl } \\
\cline { 3 - 4 } & & Lower & Upper \\
\hline T2DM duration (years)* & 1.112 & 1.083 & 1.258 \\
BMI (kg/m²) & 1.014 & 1.001 & 1.075 \\
AC (cm) & 1.029 & 1.017 & 1.102 \\
Triglycerides (mg/dL) & 1.008 & 0.981 & 1.012 \\
HDLc (mg/dL)* & 0.902 & 0.843 & 0.964 \\
LDLc (mg/dL)* & 1.108 & 1.031 & 1.210 \\
Hypertension* & 10.187 & 2.123 & 18.873 \\
Insulin-based treatment* & 10.585 & 1.995 & 16.152 \\
\hline
\end{tabular}

Note: *Predictor variable is significant both independently and as a co-factor. Abbreviations: T2DM, type 2 diabetes mellitus; BMI, body mass index; AC, abdominal circumference; HDLc, high-density lipoprotein cholesterol; LDLc, lowdensity lipoprotein cholesterol. 


\section{Discussion}

Over time, the link between various metabolic parameters and malignant neoplastic disorders has been studied. It was found that obesity is related to the hypertrophy of preexisting adipocytes. Also, obesity is linked to hyperplasia due to the formation of new adipocytes, which become hypoxic and secrete cytokines to stimulate angiogenesis into the adipose tissue. Also, they secrete several proinflammatory cytokines, such as tumor necrosis factor- $\alpha$ (TNF- $\alpha$ ), interleukin-6 (IL-6), IL-8, IL-10, macrophage inflammatory protein 1 (MIP-1), and monocyte chemoattractant protein-1 (MCP-1). These cytokines secreted by adipocytes are known to promote IR and increase circulating TG, which are MetS characteristics. ${ }^{21,22}$

Since it was shown that IGF-1 receptors are present on various human cancers, there can be some insulin effects on cancer cell proliferation in vivo, which may generate an indirect mechanism, such as IGF-1 stimulation. The primary stimulus for IGF-1 production in the liver is the growth hormone, and insulin can stimulate the production of IGF-1 by up-regulating growth hormone receptors in the liver. Also, hyperinsulinemia can increase IGF-1 by decreasing the hepatic secretion of IGF-binding protein (IGFBP)- 1 and $-2 .{ }^{23}$

It has been established that there is a relationship between inflammation and several types of cancer, such as the pancreatic, gastric, liver, bladder, and colorectal cancers since inflammation influences growth, apoptosis, and proliferation of tumor and stromal cells. Also, COX-2 overexpression was found in several types of human cancers, such as pancreatic, colon, and breast cancer. The contribution of COX-2 to cancer cells and the malignant type of tumor cells have been found to be related to several factors, such as modulation of inflammation and immune function as well as the growth of tumor cell invasiveness. ${ }^{24}$

The Third National Health and Nutrition Examination Survey (NHANES) demonstrated that about 47 million US residents have the MetS, with the highest prevalence of $43.5 \%$ in people over the age of $60 .{ }^{25}$ Recently, various studies were published, indicating a relationship between MetS components and cancer risk. However, epidemiologic studies linking MetS to cancer are still deficient. In recent years, a large study that enrolled 16,677 patients who were under treatment for hyperlipidemia, DM, and AHT was conducted. The patients were followed for up to 8 years. A total number of 823 of cancer occurred during the study, including pancreatic cancer in males (standardized incidence ratio 178
[114-266]) and colorectal cancer in females (standardized incidence ratio 133 [101-170]). ${ }^{26}$

A cohort study published in the USA examined the association between HDLc levels and the incidence of lung cancer in 14,547 members of Atherosclerosis Risk in Communities. Low HDLc levels $(<20 \mathrm{mg} / \mathrm{dl})$ are correlated with a high risk of malignancies, having an odds ratio of $6.68 \%(95 \%$ CI $1.8-24.5, p=0.004) .{ }^{27-29}$

High TG values were correlated with higher breast cancer risk in postmenopausal women, as well as a prostate cancer risk in men. ${ }^{30} \mathrm{~A}$ large study consisting of 368,277 participants found out that both weight and BMI were strongly correlated with the risk of colon cancer in men. In all genders, AC was positively associated with colon cancer risk. ${ }^{31}$ Abdominal obesity represents an independent risk factor for precancerous lesions in the colon. ${ }^{32}$

After adjustment of the increased prevalence of metabolic abnormalities with age, as well as after additional adjustment of all variables, the hazard ratios (HR) for two metabolic abnormalities, respectively three or four metabolic abnormalities compared to no metabolic abnormalities were 1.4, according to the data from the Physicians' Health Study (22,046 male physicians). A BMI of $27 \mathrm{~kg} / \mathrm{m}^{2}$ or higher and the presence of diabetes were independently associated with an increased risk of colorectal cancer with HRs of 1.4 (95\% CI, 1.1-1.7) and 1.5 (95\% CI, 1.1-2.0), respectively. Elevated blood pressure was associated with a slightly higher risk (HR, 1.1; 95\% CI, 0.9-1.3). ${ }^{33}$

The incidence of T2DM and MetS has risen over the past few decades as a result of the obesity epidemic in both developing and industrialized countries. In a systematic review about DM and the risk of breast cancer, Xue et al noted a modest link between T2DM and the incidence of breast cancer. A meta-analysis of all available studies indicates that women with a DM history display an approximately $16 \%$ higher risk of developing breast cancer than women without any personal DM history, and this risk was highest among postmenopausal women and those with T2DM. ${ }^{34}$ There have also been abundant data showing that various components of MetS and IR, including fasting insulin levels, abdominal obesity, and lipid profile, are associated with an elevated risk of postmenopausal breast cancer. ${ }^{35}$ The biochemical mechanisms include extraglandular estrogen production, reduced sex hormonebinding globulin with consequent elevation of bioactive free estradiol levels, and increased insulin biosynthesis, all of which exert mitogenic effects on both standard and neoplastic breast epithelial cells. ${ }^{36}$ 


\section{Study Strengths and Weaknesses}

The strength of the study is including a heterogeneous group of T2DM patients, allowing for research on all MetS components. The patients were enrolled in the Diabetes Center, and regular checks took place every 3-6 months.

The weakness of the study is the lack of correlation with the antidiabetic treatment or with the complications of DM. Another weakness was the lack of research on immunohistochemical markers, such as adipokines (leptin, adiponectin), VRGF, pro-inflammatory cytokines.

\section{Relevance of Findings}

MetS is a very common condition in T2DM patients, so it is an important measure that is required to prevent its occurrence. The risks and the complications of the MetS are known, as well as those deriving from the risk of possible malignant neoplasia, and, for this reason, preventive measures are mandatory. It consists of early action on all metabolic components involved: a better lifestyle, hygiene, and diet adapted exercise depending on the person's ability, specific drug and non-drug therapies.

\section{Future Perspectives}

We intend to continue our study by analyzing other possible connections between malignant neoplastic disorders and the antidiabetic treatment, to find possible associations between malignant neoplasm types and both insulin and non-insulin diabetic treatment.

\section{Conclusions}

The prevalence of malignant neoplastic disorders in our study group was $7.1 \%$; more precisely, we found $2.2 \%$ colon cancer, $2.9 \%$ breast cancer, $0.7 \%$ lymphomas, $0.6 \%$ pulmonary cancer, $0.3 \%$ pancreatic cancer, and $0.4 \%$ prostate cancer. We found that the prevalence of malignant neoplastic disorders was higher in patients with T2DM and MetS as compared to the general population of T2DM patients. Clinical and biological monitoring via eg, regular examinations, paraclinical, and laboratory tests with a minimum frequency of six months are necessary for early detection of the associated risk factors.

\section{Disclosure}

The authors declared no potential conflicts of interest concerning the research, authorship, or publication of this article.

\section{References}

1. Calle EE, Rodriguez C, Walker-Thurmond K, Thun MJ. Overweight, obesity, and mortality from cancer in a prospectively studied cohort of U.S. adults. $N$ Engl J Med. 2003;348:1625-1638. doi:10.1056/ NEJMoa021423

2. World Cancer Report Boyle P, Bernard L, editors. Eds. Cedex, France, World Health Organization, International Agency for Research on Cancer. 2008; Available from http://www.iarc.fr/en/pub lications/pdfs-online/wcr/index.php.

3. Willi C, Bodenmann P, Ghali WA, Faris PD, Cornuz J. Active smoking and the risk of type 2 diabetes: a systematic review and meta-analysis. JAMA. 2007;298:2654-2664. doi:10.1001/ jama.298.22.2654

4. Foy CG, Bell RA, Farmer DF, Goff DC, Wagenknecht LE. Smoking and incidence of diabetes among U.S. adults: findings from the Insulin Resistance Atherosclerosis Study. Diabetes Care. 2005;28:2501-2507. doi:10.2337/diacare.28.10.2501

5. Food, Nutrition, Physical Activity, and the Prevention of Cancer: a Global Perspective London, World cancer research fund, American institute for cancer research. 2007; Available from http:// www.dietandcancerreport.org. Accessed April 17, 2020.

6. Park EJ, Lee JH, Yu GY, et al. Dietary and genetic obesity promote liver inflammation and tumorigenesis by enhancing IL-6 and TNF expression. Cell. 2010;140:197-208. doi:10.1016/j.cell.2009.12.052

7. Calle EE, Kaaks R. Overweight, obesity and cancer: epidemiological evidence and proposed mechanisms. Nat Rev Cancer. 2004;4:579-591. doi:10.1038/nrc1408

8. Eliassen AH, Colditz GA, Rosner B, Willett WC, Hankinson SE. Adult weight change and risk of postmenopausal breast cancer. JAMA. 2006;296:193-201.

9. Vander Heiden MG, Cantley LC, Thompson CB. Understanding the Warburg effect: the metabolic requirements of cell proliferation. Science. 2009;324:1029-1033. doi:10.1126/science.1160809

10. Vigneri P, Frasca F, Sciacca L, Pandini G, Vigneri R. Diabetes and cancer. Endocr Relat Cancer. 2009;16:1103-1123. doi:10.1677/ERC09-0087

11. Cox ME, Gleave ME, Zakikhani M, et al. Insulin receptor expression by human prostate cancers. Prostate. 2009;69:33-40. doi:10.1002/ pros. 20852

12. Hamman RF, Wing RR, Edelstein SL, et al. Effect of weight loss with lifestyle intervention on risk of diabetes. Diabetes Care. 2006;29:2102-2107. doi:10.2337/dc06-0560

13. Kim JH, Lim YJ, Kim Y-H, et al. Is metabolic syndrome a risk factor for colorectal adenoma? Cancer Epidemiol Biomarkers Prev. 2007;16:1543-1546. doi:10.1158/1055-9965.EPI-07-0199

14. Denley A, Carroll JM, Brierley GV, et al. Differential activation of insulin receptor substrates 1 and 2 by insulin-like growth factor-activated insulin receptors. Mol Cell Biol. 2007;27:3569-3577. doi:10.1128/MCB.01447-06

15. Giovannucci E. Insulin, insulin-like growth factors and colon cancer: a review of the evidence. $J$ Nutr. 2001;131:3109S-3120S. doi:10.1093/jn/131.11.3109S

16. Renehan AG, Frystyk J, Flyvbjerg A. Obesity and cancer risk: the role of the insulin-IGF axis. Trends Endocrinol Metab. 2006;17:328-336. doi:10.1016/j.tem.2006.08.006

17. Paonessa F, Foti D, Costa V, et al. Activator protein-2 overexpression accounts for increased insulin receptor expression in human breast cancer. Cancer Res. 2006;66(10):5085-5093. doi:10.1158/00085472.CAN-05-3678

18. Pollak M. Insulin and insulin-like growth factor signalling in neoplasia. Nat Rev Cancer. 2008;8:915-928. doi:10.1038/nrc2536

19. van Kruijsdijk RC, van der Wall E, Visseren FL. Obesity and cancer: the role of dysfunctional adipose tissue. Cancer Epidemiol Biomarkers Prev. 2009;18:2569-2578. doi:10.1158/1055-9965.EPI09-0372 
20. Morita T, Tabata S, Mineshita M, et al. The metabolic syndrome is associated with increased risk of colorectal adenoma development: the self- defense forces health study. Asian Pac J Cancer Prev. 2005;6:485-489.

21. Mendonça FM, de Sousa FR, Barbosa AL, et al. Metabolic syndrome and risk of cancer: which link? Metabolism. 2015;64(2):182-189. doi:10.1016/j.metabol.2014.10.008

22. Mardilovich K, Pankratz SL, Shaw LM. Expression and function of the insulin receptor substrate proteins in cancer. Cell Commun Signal. 2009;7:14. doi:10.1186/1478-811X-7-14

23. Arcidiacono B, Iiritano S, Nocera A, et al. Insulin resistance and cancer risk: an overview of the pathogenetic mechanisms. Exp Diabetes Res. 2012;2012:1-12. doi:10.1155/2012/789174

24. Xu XC. COX-2 inhibitors in cancer treatment and prevention a recent development. Anticancer Drugs. 2002;13:127-137. doi:10.1097/ 00001813-200202000-00003

25. Ford ES, Giles WH, Dietz WH. Prevalence of the metabolic syndrome among US adults: findings from the third National Health and Nutrition Examination Survey. JAMA. 2002;287:356-359. doi:10.1001/jama.287.3.356

26. Russo A, Autelitano M, Bisanti L. Metabolic syndrome and cancer risk. Eur J Cancer. 2008;44:293-297. doi:10.1016/j.ejca.2007.11.005

27. Friedenreich CM, Orenstein MR. Physical activity and cancer prevention: etiologic evidence and biological mechanisms. J Nutr. 2002;132:3456S-3464S. doi:10.1093/jn/132.11.3456S

28. Kucharska-Newton AM, Rosamond WD, Schroeder JC, et al. HDLcholesterol and the incidence of lung cancer in the atherosclerosis risk in communities (ARIC) study. Lung Cancer. 2008;61:292-300. doi:10.1016/j.lungcan.2008.01.015
29. Shor R, Wainstein J, Oz D, et al. Low HDL levels and the risk of death sepsis and malignancy. Clin Res Cardiol. 2008;97:227-233. doi:10.1007/s00392-007-0611-z

30. Gaard M, Tretli S, Urdal P. Risk of breast cancer in relation to blood lipids: a prospective study of 31209 Norwegian women. Cancer Causes Control. 1994;5:501-509. doi:10.1007/BF01831377

31. Pischon T, Lahmann PH, Boeing H, et al. Body size and risk of colon and rectal cancer in the European Prospective Investigation Into Cancer and Nutrition (EPIC). J Natl Cancer Inst. 2006;98:920-931. doi:10.1093/jnci/djj246

32. Suchanek S, Grega T, Ngo O, et al. How significant is the association between metabolic syndrome and prevalence of colorectal neoplasia? World J Gastroenterol. 2016;22(36):8103-8111. doi:10.3748/wjg. v22.i36.8103

33. Sturmer T, Buring JE, Lee I-M, et al. Metabolic abnormalities and risk for colorectal cancer in the physicians' health study. Cancer Epidemiol Biomarkers Prev. 2006;15:2391-2397. doi:10.1158/10559965.EPI-06-0391

34. Xue F, Michels KB. Diabetes metabolic syndrome and breast cancer: a review of the current evidence. Am J Clin Nutr. 2007;86:s823-s835. doi:10.1093/ajcn/86.3.823S

35. Lawlor DA, Smith GD, Ebrahim S. Hyperinsulinaemia and increased risk of breast cancer: findings from the British Women's Heart and Health Study. Cancer Causes Control. 2004;15:267-275. doi:10.1023/B:CACO.0000024225.14618.a8

36. Vona-Davis L, Howard-McNatt M, Rose DP. Adiposity type 2 diabetes and the metabolic syndrome in breast cancer. Obes Rev. 2007;8:395-408. doi:10.1111/j.1467-789X.2007.00396.x

\section{Publish your work in this journal}

Diabetes, Metabolic Syndrome and Obesity: Targets and Therapy is an international, peer-reviewed open-access journal committed to the rapid publication of the latest laboratory and clinical findings in the fields of diabetes, metabolic syndrome and obesity research. Original research, review, case reports, hypothesis formation, expert opinion and commentaries are all considered for publication. The manuscript management system is completely online and includes a very quick and fair peer-review system, which is all easy to use. Visit http://www.dovepress.com/testimonials.php to read real quotes from published authors.

Submit your manuscript here: https://www.dovepress.com/diabetes-metabolic-syndrome-and-obesity-targets-and-therapy-journal 